«Системні технології» 2 (127) 2020 «System technologies»

DOI 10.34185/1562-9945-2-127-2020-06

УДК 004.942:519.816

М.В. Андрюхіна, Г.Л. Євтушенко, В.І. Кузнецов

\title{
ОГЛЯД МЕТРИК ТА АНАЛІЗ ЇХНЬОГО ВИКОРИСТАННЯ ПРИ ОЦІНЦІ ЕФЕКТИВНОСТІ ІТ-ПРОЕКТІВ
}

Анотація. У статті виділені основні показники при оцінці ефективності IT-проектів. Зібрані дані про сучасні метрики, які успішно використовують великі IT-компанії. Розкривається поняття "ієрархія метрик", показаний зв'язок з ієрархією методології BOCR, що використовується для оцінки ефективності.

Проведений огляд сучасних метрик в IT-галузі та розглянута проблема підбору успішних метрик, які в сумі будуть найбільш повною мірою описувати основні аспекти ефективності IT-проектів.

Запропоновані метрики за узагальненими показниками, які успішно використовують у практиці IТ-компанії. Приводяться аргументи щодо використання запропонованих метрик в реальному менеджменті в IT-компаніях.

Ключові слова: метрика програмного забезпечення, вимірювання успіху проекту, ефективність, IT-проекти, оцінка.

Постановка проблеми в загальному вигляді та її зв'язок 3 важливими науковими або практичними завданнями. Існують безліч способів, за допомогою яких можна підходити до управління проектами, і за останні 60 років було розроблено безліч методологій i процесів розробки ІТ-проектів. [6]

Разом 3 тим слід зазначити, що на цей час немає єдиної моделі оцінки ефективності IT-проекту. Відсутність єдиного способу оцінки ефективності ІТ-проектів значно ускладнює процес прийняття рішень про доцільність реалізації певного проекту. Ефект, визначений різними методологіями може значно відрізнятися. Тому проблема правильного підбору потрібних метрик та (або) розробки нових є актуальною.

Аналіз останніх досліджень і публікацій, в яких покладений початок вирішенню даної проблеми і на які спирається автор. Мет-

(C) Андрюхіна М.В., Євтушенко Г.Л., Кузнецов В.І., 2020 
«Системні технології» 2 (127) 2020 «System technologies»

рики - це якісні чи кількісні показники, які відображають різні характеристики продукту. Метрики потрібні, щоб ефективно управляти проектом: діагностувати проблеми, локалізувати їх, виправляти і перевіряти, чи допомагають вибрані вами способи у вирішенні проблеми. Існує багато публікацій (у тому числі електронних), які пропонують способами вирішення проблеми раціональної та точної оцінки ефективності ITпроектів.

Оскільки кількісні методи добре зарекомендували себе в інших областях, багато теоретиків і практиків інформатики намагалися перенести даний підхід і в розробку програмного забезпечення. Як сказав Том ДеМарко (програміст з Пенсильванії, США), «ви не можете контролювати те, що не можете виміряти».

У статті Ковальчук Н.В. "Оцінка ефективності IT-інвестицій в проектах автоматизації" відмічена користь якісних (евристичних) методів оцінки, переваги яких полягає у доповненні кількісних [10].

Шам К. у своїй роботі про "Практичний підхід до управління показниками проектів" розглядає основні вимоги i проблеми при впровадженні метрик управління проектами. Докладно розглядається кожна метрика, пояснюється, що саме вимірюється, процес збору даних, комунікації (частота і аудиторія), проблеми, з якими стикаються, і засоби контролю на місці. Також, зазначається, що метрики управління проектами є ключем до поліпшення якості їхньої реалізації [1].

Клоппернборг, Т.Дж., Теш, Д. та Кинг, В. в роботі про "Заходи успіху проекту XXI століття: еволюція, інтерпретація, напрямок" аналізують як фахівці 3 управління проектами визначають фактори успіху проекту, відповідаючи на наступні питання: Чи є раніше певні показники успіху заходами, використовуваними нинішніми практиками? Чи є деякі показники успіху важливіше інших? Як ці показники успіху залежать від галузі або типу проекту? Також, метою їх дослідження було зрозуміти, які показники успіху найбільш важливі для практиків і чому ці фактори можуть коливатися в залежності від стадії проекту [2].

У статті Чопри К. та Сачдева М. (2015) на тему "Оцінка метрик програмного забезпечення для програмних проектів", що представлена в 


\section{«Системні технології» 2 (127) 2020 «System technologies»}

Міжнародному журналі комп'ютерів і технологій, запропоновані найпоширеніші програмні метрики та розглядається їх використання при побудові моделей процесу розробки програмного забезпечення [4].

Міжнародний журнал управління проектами [5] детально розглядає такі поняття, як "успішний проект", "цілі проекту", "продуктивність" з точки зору проектного менеджменту.

Велику інформативну цінність має стаття Судхакара Г.П. (2016) за темою "Розуміння значення «Успіх проекту»" де згруповані та обговорені роботи Джеффі К. Пінто та Денніса П. Слєвіна, Девіда і Адама, Делоне і Маклін та дослідження групи Standish [8].

Виділення невирішених раніше питань, що є частиною загальної проблеми, яким присвячується стаття. У вищезгадані наукових працях зазначені найпопулярніші аспекти за якими рекомендовано проводити ефективність ІТ-проектів, доцільність їх інвестування, 3 огляду на практичний досвід великих успішних IT-компаній. Автори приводять свої доводи, щодо доцільності використання тих, чи інших метрик в певних ситуаціях, але не пропонують узагальнюючу систему метрик, що пов'язані між собою певними залежностями, яка б дозволила найбільш повно дати оцінку ефективності проекту.

Метою даної статті $\epsilon$ дослідження різних аспектів в оцінці ефективності ІТ-проекту та побудова узагальнюючої системи взаємозалежних метрик, за якою можна контролювати перебіг успішності процесів в життєвому циклі IT-проекту та своєчасно робити оцінку його ефективності.

Викладення основного матеріалу дослідження 3 повним обгрунтуванням отриманих наукових результатів.

Метрики управління проектами мають важливе значення для реалізації практичних і стійких практик і процесів управління проектами в будь-якій організації. Ключ у тому, що метрики повинні бути простими, практичними актуальними для організації [1].

Звернемося до зарубіжного досвіду і розглянемо запропоновані підходи до оцінки ефективності проектів. 
«Системні технології» 2 (127) 2020 «System technologies»

Зазвичай при виборі метрик орієнтуються на три основні чинники:

1) Тип продукту;

2) Етап його розвитку;

3) Цілі бізнесу.

Метрики можна поділити на різні категорії. Наприклад, бувають продуктові, маркетингові та бізнес-метрики. У статті розглядаються тематичні метрики - за програмними цілями розробки, яких вони допомагають досягти.

3 тематичних метрик, можна виділити ті, що показують дані залучення користувачів. Вони допомагають зрозуміти, як і звідки в продукт приходять користувачі, скільки їх всього, які з них активні.

Приклади метрик залучення користувачів, метрик використання продукту та метрик монетизації розглядаються у статті Іраідіної М. на тему "Що таке продуктові метрики і навіщо вони потрібні" [11]. До метрик використання продукту входять всі показники, які демонструють, як люди користуються продуктом, які є сценарії.

У нашому випадку продукт - IT-проект, в якому визначена певна ціль. Розроблена узагальнена структура показників ефективності ITпроектів, за якими можна будувати метрики (рис. 1).

На рисунку 2 приведені узагальнені дані командних процесів по яким рекомендовано будувати метрики у статті Судхакара "Розуміння значення «Успіх проекту»".

Найбільше уваги зазвичай приділяється метрикам якості програмних продуктів. Адже це, основна складова якості IT-проектів.

Метрика програмного забезпечення (англ. Software metric) - захід, що дозволяє отримати чисельне значення властивості програмного забезпечення або його специфікацій.

В даний час в програмної інженерії ще не сформувалася остаточно система метрик. Діють різні підходи до визначення їх набору і методів вимірювання. Система вимірювання включає метрики i моделі вимірювань, які використовуються для кількісної оцінки якості ПЗ [3]. 
«Системні технології» 2 (127) 2020 «System technologies»

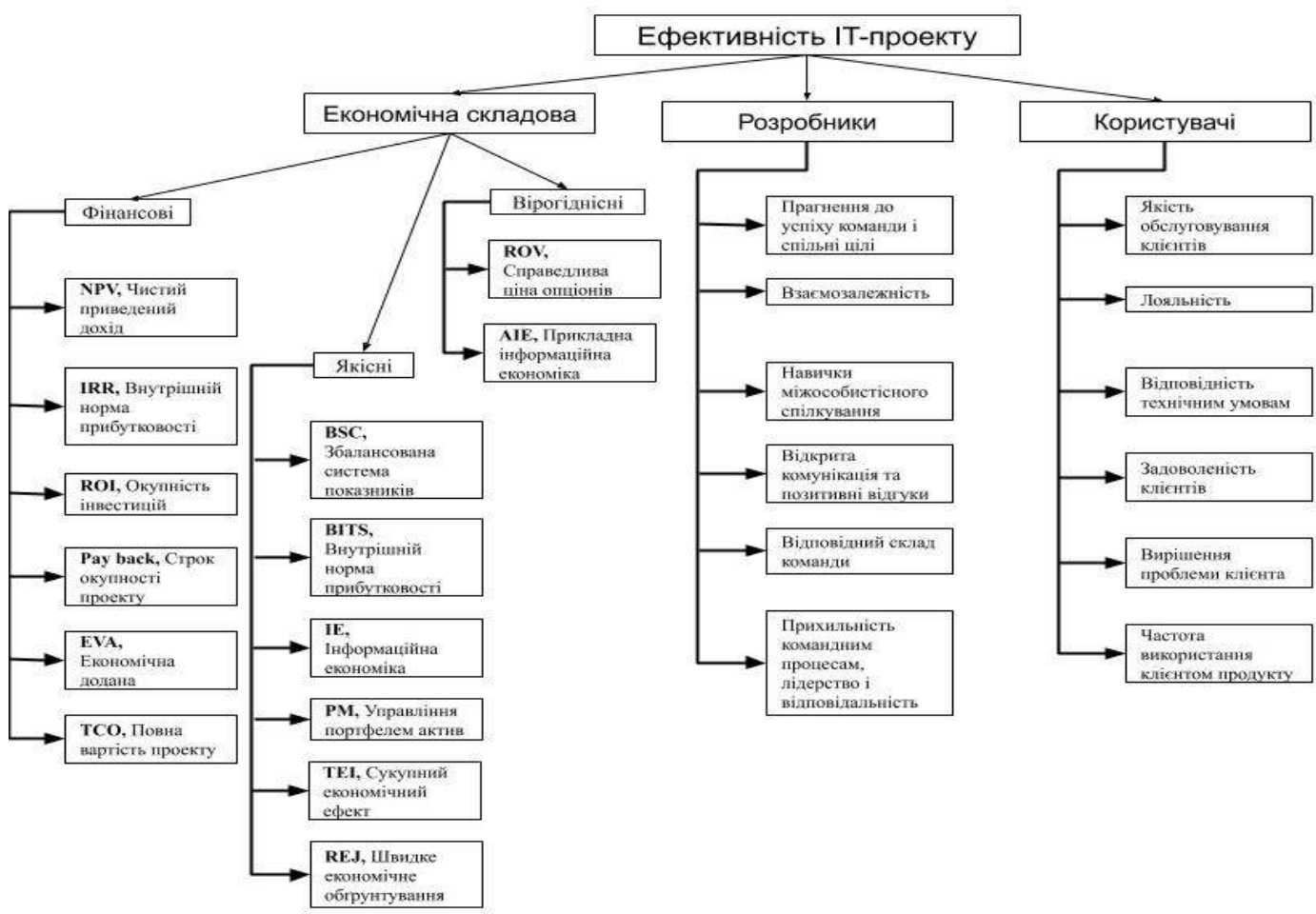

Рисунок 1 - Узагальнена структура показників ефективності IT-проектів

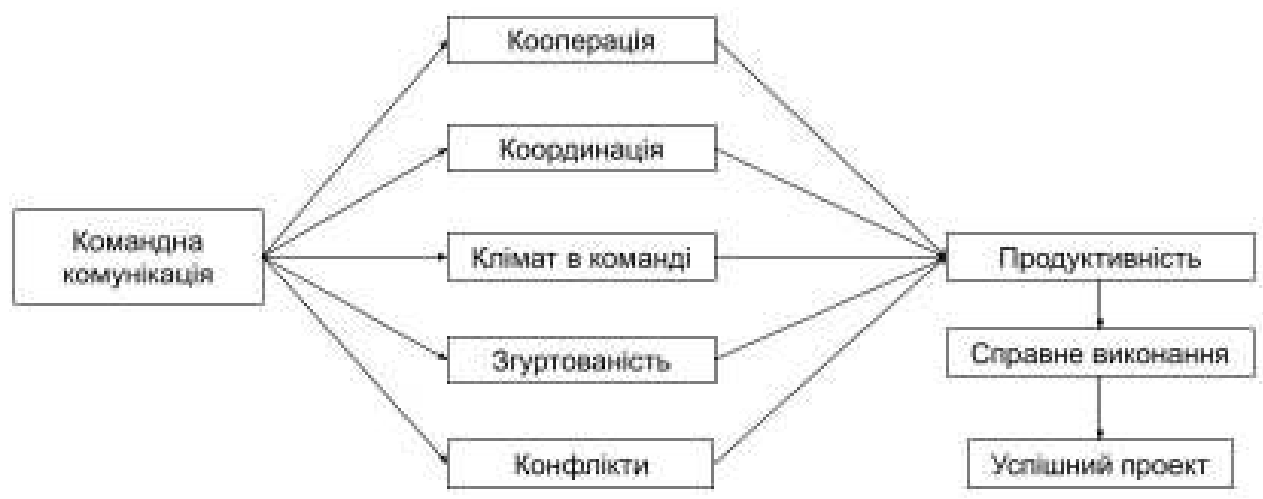

Рисунок 2 - Вплив командних процесів на успіх проекту

Методи оцінки якісними показниками дозволяють розробникам та спеціалістам в цій галузі самостійно вибирати найбільш важливі характеристики IT-систем і проектів, в залежності від специфіки роботи встановити взаємозалежності, співвідношення між ними, наприклад, за допомогою коефіцієнтів значущості [10]. Це дає змогу провести аналогію 3 методами багатокритеріального аналізу, наприклад, з методологією BOCR [13], ієрархія методології представлена на рисунку 3. 


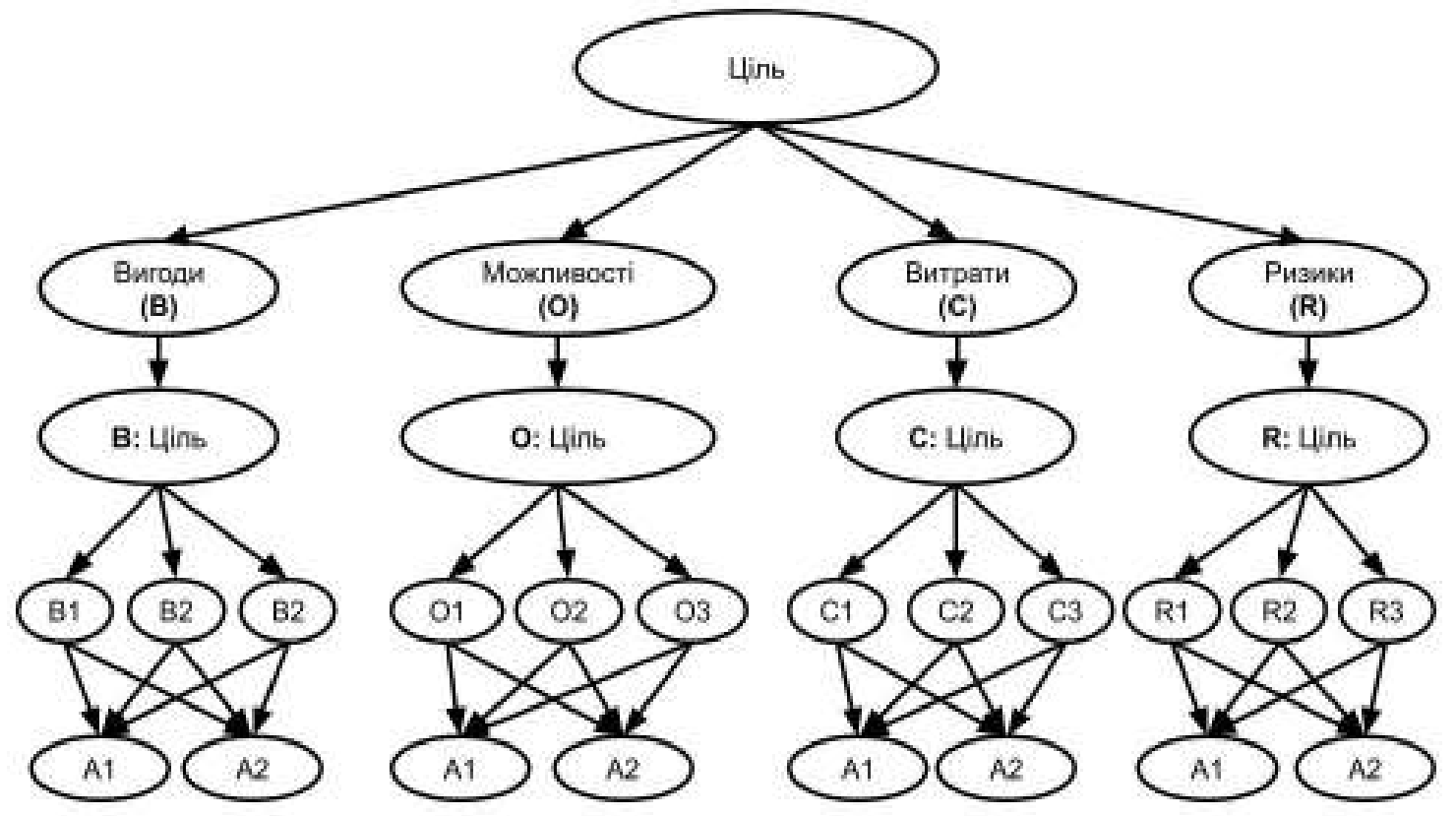

Рисунок 3 - Ієрархія методології BOCR

Існує три типи метрик:

- метрики програмного продукту, які використовуються при вимірюванні його характеристик - властивостей;

- метрики процесу, які використовуються при вимірюванні властивості процесу ЖЦ створення продукту.

- метрики використання.

Метрики - це просто числа, які самі по собі не дають важливої інформації. Щоб від них була користь, всі показники потрібно дивитися в динаміці, вибрати певний період і проаналізувати, як змінилася метрика за цей час, що відбувалося з іншими показниками і в чому може бути причина.

Треба зазначити таке поняття, як ієрархія метрик. Ієрархія метрик - це деревоподібна структура або схема, на чолі якої знаходиться основна метрика продукту. Для її побудови, необхідно проаналізувати дані і зрозуміти реальні залежності між існуючими метриками в проекті. Ієрархія метрик дозволяє локалізувати причини змін на графіках важливих метрик ("розслідувати аномалії") та не робити зміни в проекті, що можуть нашкодити всій компанії [11]. Ієрархія метрик дозволяє тісно 


\section{«Системні технології» 2 (127) 2020 «System technologies»}

пов'язати метрики 3 оцінкою ефективності IT-проектів за допомогою методів багатокритеріального аналізу, наприклад, методології BOCR.

Методологія BOCR застосовується саме для оцінки ефективності проектів. Характерною рисою даної методології $є$ те, що при оцінці ефективності враховуються не тільки явні, але і додаткові можливості і можливі ризики. Спільне застосування всіх чотирьох аспектів в аналізі рішень позначається абревіатурою BOCR (Benefits - Opportunities - Costs Risks), в якій на перших місцях розташовані вигоди і можливості, а потім витрати і ризики. Кожен з них вносить вклад в якість рішення і повинен розглядатися окремо 3 використанням набору (впорядкованих за пріоритетами) критеріїв, які можуть застосовуватися для аналізу будьяких інших рішень [12].

BOCR програмно реалізовано у системі підтримки прийняття рішень NooTron [12]. За допомогою BOCR можна порівнювати розглядати метрики для різних наборів кількісних та якісних даних, використовуючи зв'язки між ними, загальною метою та критеріями ефективності. Коефіцієнти значущості для кожної компанії різні і можуть визначатися самостійно (експертно або за методом аналізу ієрархій, який є складовою частиною BOCR. Для побудови структури проблеми її аспекти можуть бути, наприклад, такими, які представлені в узагальненій структурі показників ефективності ІТ-проектів на рисунку 1 та (або) на рисунку 2.

Висновки 3 даного дослідження і перспективи подальших розробок за даним напрямом. Контроль успішності протікання життєвого циклу IT-проекту в цілому, складається з різних аспектів, один 3 яких саме програмна складова. Існує безліч різних метрик, які можуть представляти цінність для управління сучасним процесом.

Успішні ІТ-організації вирішують подібні проблеми до того, як вони стають проблемами, в той час як менш успішні організації застають зненацька, коли бізнес скаржиться на погіршення їх технологій. Метрики $€$ ключем до активного усунення симптомів до того, як вони стануть суттєвими проблемами і переросли у кризу.

В статті досліджені існуючі сучасні метрики, що успішно використовуються провідними спеціалістами в менеджменті, в IT-компаніях. 86 
«Системні технології» 2 (127) 2020 «System technologies»

Представлений свій варіант узагальненої структури показників ефективності ІТ-проектів, за якою рекомендується будувати метрики та проводити оцінку ефективності ІТ-проектів.

\section{ЛИТЕРАТУРА / ЛІТЕРАТУРА}

1. Sham, K. (2013). Practical approach to project management metrics. Paper presented at PMI ${ }^{\circledR}$ Global Congress 2013-North America, New Orleans, LA. Newtown Square, PA: Project Management Institute.

2. Kloppenborg, T. J., Tesch, D., \& King, B. (2012). Twenty-first century project success measures: evolution, interpretation, direction. Paper presented at PMI ${ }^{\circledR}$ Research and Education Conference, Limerick, Munster, Ireland. Newtown Square, PA: Project Management Institute.

3. Петрухин, B.А., Лаврищева, Е.М. Методы и средства инженерии программного обеспечения Методи і засоби інженерії програмного забезпечення [Электронная книга]. - Режим доступа: https://www.intuit.ru/goods_store/ebooks/8367.

4. Chopra, K., \& Sachdeva, M. (2015). Evaluation of software metrix for software projects. International journal of computers \& technology, 14(6). P. 5845-5853. - https://doi.org/10.24297/ijct.v14i6.1915.

5. Anton de Wit. Measurement of project success. // International Journal of Project Management. - Elsevier, August 1988. - Volume 6, Issue 3. Pages 164-170. - https://doi.org/10.1016/0263-7863(88)90043-9.

6. Шан Гао, Лазар Русу. Сучасні методи успішного управління ITпроектами, Видавництво: IGI Global. - 2015 року, С. 80.

7. Бадлаева О. А., Чуева А. Д. Основные подходы к оценке эффективности информационных систем // Молодой ученый. - 2016. - №27.2. - С. 5-7. - URL https://moluch.ru/archive/131/36431/ .

8. Sudhakar G.P. (2016). Understanding the Meaning of "Project Success", Binus University, 7 (2), 163-169. http://dx.doi.org/10.21512/bbr.v7i2.1586.

9. Ковальчук, Н.В. Оценка эффективности IT-инвестиций в проектах автоматизации. // Прикладная информатика. - 2009. - № 3 (21).

10. Ираидина, М. Что такое продуктовые метрики и зачем они нужны: [Электронный ресурс]. - Режим доступа: 
«Системні технології» 2 (127) 2020 «System technologies»

https://skillbox.ru/media/management/chto_takoe_produktovye_metriki_i_zac hem_oni_nuzhny/

11. Андрюхіна M.В. Система підтримки прийняття рішень ProjectEvaluation для багатокритеріальної оцінки ефективності ITпроектів на базі спрощеного варіанту методології BOCR // Збірка тез доповідей XIII Міжнародної науково-практичної конференції «Сучасні інформаційні та комунікаційні технології на транспорті, в промисловості та освіті», 11 - 12 грудня 2019 року. - м. Дніпро: ДНУЗТ, 2019. - С.49.

12. Саати Т.Л. Принятие решений при зависимостях и обратных связях: Аналитические сети. - М.: Изд-во ЛКИ, 2008. - 360 с.

13. Драч, I.Є. Багатокритеріальний аналіз ефективності портфелів наукових проектів вищого навчального закладу [Текст] / І.Є. Драч, Г.Л. Євтушенко // Управління розвитком складних систем.-2015. - № 22(1) -С. 33-41. 14. Андрюхіна М.В. "Дослідження багатокритеріальних методів для оцінки ефективності проектів". Магістерська робота, НМетАУ, 2019.

15. СППР Nootron [Електронний ресурс]. - Режим доступу до матер.: http://nootron.net.ua/ .

\section{REFERENCES}

1. Sham, K. (2013). Practical approach to project management metrics. Paper presented at PMI ${ }^{\circledR}$ Global Congress 2013-North America, New Orleans, LA. Newtown Square, PA: Project Management Institute.

2. Kloppenborg, T. J., Tesch, D., \& King, B. (2012). Twenty-first century project success measures: evolution, interpretation, direction. Paper presented at PMI ${ }^{\circledR}$ Research and Education Conference, Limerick, Munster, Ireland. Newtown Square, PA: Project Management Institute.

3. Petrukhyn V.A., Lavryshcheva E.M. Metodы y sredstva ynzheneryy prohrammnoho obespechenyia Metody i zasoby inzhenerii prohramnoho zabezpechennia [כlektronnaia knyha]. - Rezhym dostupa: https://www.intuit.ru/goods_store/ebooks/8367 .

4. Chopra, K., \& Sachdeva, M. (2015). Evaluation of software metrix for software projects. International journal of computers \& technology, 14(6). - P. 5845-5853. - https://doi.org/10.24297/ijct.v14i6.1915. 
«Системні технології» 2 (127) 2020 «System technologies»

5. Anton de Wit. Measurement of project success. // International Journal of Project Management. - Elsevier, August 1988. - Volume 6, Issue 3.- Pages 164-170. - https://doi.org/10.1016/0263-7863(88)90043-9.

6. Shan Hao, Lazar Rusu. Suchasni metody uspishnoho upravlinnia ITproektamy, Vydavnytstvo: IGI Global. - 2015 roku, S.-80.

7. Badlaeva O. A., Chueva A. D. Osnovnыe podkhodы k otsenke эffektyvnosty ynformatsyonnыkh system // Molodoi uchenыi. - 2016. - №27.2. - S. 5-7. - URL https://moluch.ru/archive/131/36431/.

8. Sudhakar G.P. (2016). Understanding the Meaning of "Project Success", Binus University, 7 (2), 163-169. http://dx.doi.org/10.21512/bbr.v7i2.1586

9. Kovalchuk, N.V. Otsenka effektivnosti IT-investitsiy $\mathrm{v}$ proektah avtomatizatsii. // Prikladnaya informatika. - 2009. - \# 3 (21).

10. Iraidina, M. Chto takoe produktovyie metriki i zachem oni nuzhnyi: [Elektronnyiy resurs]. - Rezhim dostupa:

https://skillbox.ru/media/management/chto_takoe_produktovye_metriki_i_zac hem_oni_nuzhny/

11. Andriukhina M.V. Systema pidtrymky pryiniattia rishen ProjectEvaluation dlia bahatokryterialnoi otsinky efektyvnosti IT-proektiv na bazi sproshchenoho variantu metodolohii BOCR // Zbirka tez dopovidei XIII Mizhnarodnoi naukovo-praktychnoi konferentsii «Suchasni informatsiini ta komunikatsiini tekhnolohii na transporti, v promyslovosti ta osviti», 11 - 12 hrudnia 2019 roku. - m. Dnipro: DNUZT, 2019. - C.49

12. Saati T.L. Pryiniattia rishen pry zalezhnostiakh i zvorotnykh zviazkakh: Analitychni merezhi. - M .: Vydannia LKI, 2008. - 360 s.

13. Drach, I.Ie. Bahatokryterialnyi analiz efektyvnosti portfeliv naukovykh proektiv vyshchoho navchalnoho zakladu [Tekst] / I.Ie. Drach, H.L. Yevtushenko // Upravlinnia rozvytkom skladnykh system. - 2015. - № 22 (1) - S. 33-41.

14. Andriukhina M.V. "Doslidzhennia bahatokryterialnykh metodiv dlia otsinky efektyvnosti proektiv". Mahisterska robota, NMetAU, 2019.

15. SPPR Nootron [Elektronnyi resurs]. - Rezhym dostupu do mater.: http://nootron.net.ua/.

Received 12.02.2020. Accepted 17.02.2020. 


\section{«Системні технології» 2 (127) 2020 «System technologies»}

\section{Обзор метрик и анализ их использования при оценке эффективности IT-проектов}

Собраны данные о современных метриках, которые успешно используют крупные IT-

компании. Раскрывается понятие "иерархия метрик", показана связь с иерархией методологии BOCR, которая используется для оценки эффективности.

Предложены метрики по обобщенным показателям в виде схемы, которые успешно используются в практике Iт-компании. Приводятся аргументы относительно использования предложенных метрик в реальном менеджменте в IT-компаниях.

\section{Overview of metrics in evaluating the effectiveness of it projects}

The problem in the mainstream visionary is no single model for evaluating the effectiveness of an IT project. The lack of a single method for evaluating the effectiveness of IT projects significantly complicates the decision-making process on the feasibility of implementing a particular project. The effect determined by different methodologies can vary significantly. There-

fore, the problem of the correct selection of the necessary metrics and (or) development of new ones is relevant.

The aim of the article. The purpose of this article is to study various aspects in assessing the effectiveness of an IT project and building a generalized system of interconnected metrics, by which you can monitor the progress of processes in the life cycle of an IT project and evaluate its effectiveness in a timely manner.

The results of the analysis. The article highlights the main indicators in assessing the effectiveness of IT projects. Data collected on modern metrics that are successfully used by major IT companies. The concept of "metric hierarchy" is described, a relation with the hierarchy of BOCR methodology used to performance evaluation is shown.

The review of modern metrics in the IT industry was carried out and the problem of selecting successful metrics was considered, which in total will most fully describe the main aspects of the effectiveness of IT projects.

The proposed metrics for generalized indicators that are successfully used in the practice of IT-companies. Arguments are given regarding the use of the proposed metrics in real management in IT companies.

Conclusions and directions for further research. Monitoring the progress of the life cycle of the IT project as a whole consists of various aspects, one of which is the software component.

Successful IT organizations solve such problems before they become problems, while less successful organizations are taken aback when a business complains about the degradation of their technology. Metrics are the key to actively eliminating symptoms before they become significant problems and develop into a crisis.

The article explores the existing modern metrics, successfully used by leading experts in management, in IT companies. Presented his version of the generalized structure of indicators of 
«Системні технології» 2 (127) 2020 «System technologies»

the effectiveness of IT projects, according to which it is recommended to build metrics and evaluate the effectiveness of IT projects.

Андрюхина Маргарита Васильевна - аспирант каф. информационных технологий и систем, Национальная металлургическая академия Украины.

Евтушенко Галина Львовна- к.т.н., доцент кафедры информационных технологий и систем, Национальная металлургическая академия Украины.

Кузнецов Владимир Иванович - к.т.н., доцент кафедры информационных технологий и систем, Национальная металлургическая академия Украины.

Андрюхіна Маргарита Василівна - аспірант каф. інформаційних технологій і систем, Національна металургійна академія України.

Євтушенко Галина Львівна - к.т.н., доцент кафедри інформаційних технологій і систем, Національна металургійна академія України.

Кузнецов Володимир Іванович - к.т.н., доцент кафедри інформаційних технологій і систем, Національна металургійна академія України.

Andryukhina Margarita - graduate student of the Department of Information Technologies and Systems, National Metallurgical Academy of Ukraine.

Yevtushenko Galina - Candidate of Technical Sciences, Associate Professor of the Department of Information Technologies and Systems, National Metallurgical Academy of Ukraine.

Kyznecov Vladimir - Candidate of Technical Sciences, Associate Professor of the Department of Information Technologies and Systems, National Metallurgical Academy of Ukraine. 